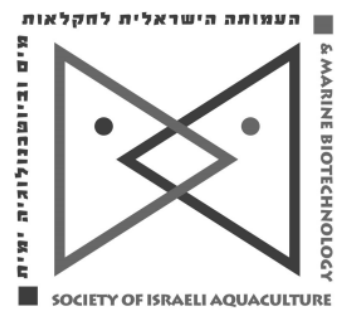

The IJA appears exclusively as a peer-reviewed on-line open-access journal at http://www.siamb.org.il/. To read papers free of charge, please register online at registration form.

Sale of $I J A$ papers is strictly forbidden.

\title{
Isolation and Characterization of Aeromonas veronii from Ornamental Fish Species in China
}

\section{Yajiao Song1,2a, Xiucai Huª, Aijun Lü2*, Jingfeng Sun², Yeong Yiksung ${ }^{2}$, Chao Pei ${ }^{1}$, Chao Zhang ${ }^{1}$, Li Li ${ }^{1}$}

a These authors contributed equally to this work

${ }^{1}$ College of Fisheries, Henan Normal University, Xinxiang, 453007, China

2 Tianjin Key Lab of Aqua-Ecology and Aquaculture, College of Fisheries, Tianjin Agricultural University, Tianjin, 300384, China

Keywords: Aeromonas veronii; ornamental fish; isolation and identification; histopathology

\begin{abstract}
Aeromonas veronii infection of fish has become a significant problem in aquaculture. In this study, pure bacterial cultures were isolated from diseased ornamental fish suffering high mortality rate in China. These fish included zebrafish (Danio rerio), goldfish (Carassius auratus), oscar (Astronotus ocellatus), parrotfish (Amphilophus spp.) and crucian carp (Cyprinus carpio koi). Using morphologic, physiological, and biochemical characteristics and $16 \mathrm{~S}$ rRNA sequences analysis, nine isolates, namely strains ZG-1, ZG-2, DW-1, DW2, KL-1, DT-116, LS-912, SJ-1 and SJ-2 were identified as A. veronii. A phylogenetic tree constructed on the basis of 16S rRNA sequences strongly indicated that the isolates were most closely related to the species $A$. veronii (98.43-100\% similarities). The pathogenicity of the isolate was confirmed in zebrafish with median lethal dose (LD 50 ) ranging between $1.15 \times 10^{6} \mathrm{CFU} / \mathrm{mL}$ and $3.94 \times 10^{8} \mathrm{CFU} / \mathrm{mL}$. Antibiotic susceptibility tests showed that the isolated strains were all susceptible to cephalosporins and chloramphenicol. Furthermore, histopathology of zebrafish showed leukocyte infiltration of gill filaments, necrosis of the hepatic cell and glomerulus hemorrhage. These results will provide a scientific reference for the prevention, control, and understanding of the pathogenic mechanism of $A$. veronii infection in fish.
\end{abstract}




\section{Introduction}

Aeromonas spp. such as $A$. veronii, $A$. hydrophila, and $A$. jandaei, were isolated from diseased fish. These are commonly considered opportunistic pathogens (Sreedharan et al., 2012; Jagoda et al., 2014; Lü et al., 2016). Of all, A. veronii is widely distributed in aquatic environments and its high pathogenicity threatens aquaculture development and human health (Suely et al., 2010; Sreedharan et al., 2012; Jagoda et al., 2014). Recently, A. veronii infection in ornamental fish caused high mortality and economic losses (MartínezMurcia et al., 2008; Lü et al., 2016; Sun et al., 2016). In ornamental fish farms the incidence of skin ulcerative disease caused by $A$. veronii is increasing characterized by internal and surface bleeding accompanied by a high mortality rate (Cai et al., 2012; Zhou et al., 2012; Sun et al., 2016).

In recent years, the ornamental fish industry has undergone rapid development and increases in China (Liu et al., 2004; Teng et al., 2007). There were reports on the isolation and characterization of $A$. veronii from diseased goldfish (Han et al., 2008; Yang, 2013; Wang et al., 2013b). Very recently, a pathogenic $A$. veronii strain CAV-134 was isolated from the ulcerative lesions and internal organs of infected goldfish in China (Lü et al., 2016). In this study, nine Gram-negative bacteria isolated from skin ulceration, dropsy, and hemorrhages of diseased ornamental fish were identified as $A$. veronii by biochemical properties and 16S rRNA sequences analysis. Pathogenicity was confirmed and the median lethal dose (LD50) was assessed in adult zebrafish by intraperitoneal injection. These studied results will provide a reference for the identification and treatment of $A$. veronii infections in ornamental fish.

\section{Materials and Methods}

Fish. From April 2013 to May 2017, diseased ornamental fish were collected from farms in Tianjin city, in China.These fish included zebrafish Danio rerio (ca. $0.50 \mathrm{~g}$ ), goldfish Carassius auratus (ca. 20g), oscar Astronotus ocellatus (ca. 53g), parrotfish Amphilophus spp. (ca. 24g) and crucian carp Cyprinus carpio koi (ca. 18g). Typical clinical signs were external hemorrhages and ulcers, mainly located on the head and ventral part of the body.

Bacterial isolation. For bacterial isolation, samples taken from livers of the moribund ornamental fish were streaked onto Luria-Bertani (LB) agar plates and incubated at $28^{\circ} \mathrm{C}$ for 18-24h; bacterial colonies were restreaked at least 3 times on LB medium until a pure culture was obtained according to the method described by Lü et al. (2016).

Physiological and biochemical tests. The isolates were examined using biochemical tubes (Hang zhou Tianhe Microorganism Reagent co., Ltd., China) with reference to Bergery's Manual of Determinative Bacteriology (Bowman et al., 2005).

$16 S$ rRNA sequence analysis. Total genomic DNA was extracted according to the method described by Queipo et al. (2008); the 16S rRNA genes were amplified with universal primers 27F: 5'AGAGTTTGATCATGGCTCAG-3' and 1492R: 5'GGTTACCTTGTTACGACTT-3'. According to the method described by Lü et al. (2011), the PCR amplification conditions were as follows: $94^{\circ} \mathrm{C}$ for $5 \mathrm{~min}, 30$ cycles of $94^{\circ} \mathrm{C}$ for $30 \mathrm{~s}$, $56^{\circ} \mathrm{C}$ for $45 \mathrm{~s}, 72^{\circ} \mathrm{C}$ for $1 \mathrm{~min}$ and final extension at $72^{\circ} \mathrm{C}$ for $10 \mathrm{~min}$ (Lü et al., 2016). The PCR products were electrophoresis with $1 \%$ agarose gel by staining with ethidium bromide. The PCR products were sequenced by GENEWIZ (China). The BLAST search was carried out at the National Center for biotechnology information (NCBI, http://www.ncbi.nih.gov/BLAST/). Phylogenetic trees were constructed using the neighbor-joining algorithm of MEGA 6.0 software, with 1000 bootstrap replicates.

Antimicrobial susceptibility test. The antimicrobial susceptibility tests for the isolate were performed using Kirby-Bauer disc diffusion method on LB nutrient agar plates, incubation at $28^{\circ} \mathrm{C}$ for $48 \mathrm{~h}$ to measure the results of the inhibition zone record (Igbinosa et al., 2013). 
Experimental challenge. The ornamental fish were experimentally infected with ZG1, ZG-2, DW-1, DW-2, KL-1, and DT-116. The treatment experiments were conducted on 310 healthy adult zebrafish. For each isolate, fifty zebrafish were divided into five groups with ten in each group and the rest were used as the control group. Experimental groups were injected intraperitoneally at a concentration of $1.96 \times 10^{6} \mathrm{CFU} / \mathrm{mL}, 1.96 \times 10^{7} \mathrm{CFU} / \mathrm{mL}$, $1.96 \times 10^{8} \mathrm{CFU} / \mathrm{mL}, 1.96 \times 10^{9} \mathrm{CFU} / \mathrm{mL}, 1.96 \times 10^{10} \mathrm{CFU} / \mathrm{mL}$, respectively. The dose for the infection was $10 \mu \mathrm{L} /$ fish. The control groups were injected with physiological saline. The zebrafish were observed daily for 7 days after infection; the moribund specimens were subjected to routine bacteriological examination for re-isolation of the liver.

Histopathology. According to the method described by Han et al. (2017), four organs (ie., gill, skin, liver, kidney) were collected from moribund zebrafish tissues during the experimental treatment and were preserved in Bonn's liquid for histological study. Tissues were dehydrated in a tert-Butanol series. Serial sections of paraffin-embedded tissues of $5 \mu \mathrm{m}$ thicknesses were cut using a microtome (Thermo, American) and stained with hematoxylin and eosin (H\&E) and examined under a light microscope.

\section{Results}

Morphologic characteristics of the isolates. Nine isolates (ie., ZG-1, ZG-2, DW-1, DW-2, $\mathrm{KL}-1, \mathrm{DT}-116, \mathrm{LS}-912, \mathrm{SJ}-1$ and SJ-2) were taken from the ornamental fish; all were Gramnegative and rod-shaped bacteria. A representative strain ZG-2 is shown in Figure 1 . The pure culture produced circular, convex, and light yellow medium sized colonies on LB agarplates after incubation at $28^{\circ} \mathrm{C}$ for $18-24 \mathrm{~h}$.

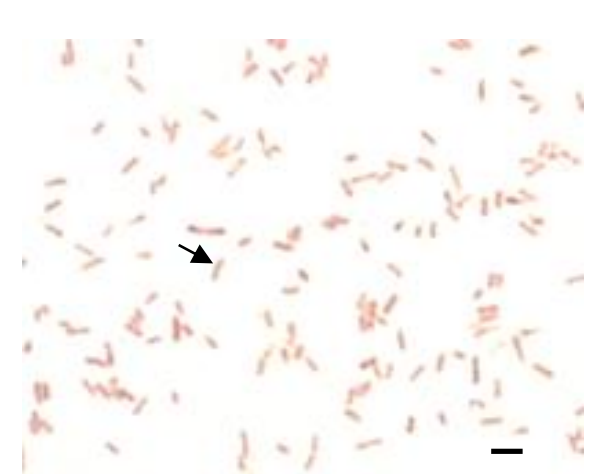

Figure 1. Strain ZG-2 was stained as Gram-negative short rod-shaped cells (arrow). Bar scale $=2 \mu \mathrm{m}$

Physiological and biochemical properties. The physiological and biochemical properties indicated that the eight isolates, ZG-1, ZG-2, DW-1, KL-1, DT-116, LS-912, SJ1 and $S J-2$ were negative for ornithine decarboxylase, but $D W-2$ was positive. The isolates ZG-1, ZG-2, DT-116, LS-912, SJ-1 and SJ-2 were positive for esculin. ZG-1 and ZG-2 were the positive for salicin, but DT-116, LS-912, SJ-1 and SJ-2 were negative. The physiological and biochemical characteristics of the nine isolates are listed in Table 1. 
Table 1. The physiological and biochemical characteristics of the isolates from the ornamental fish

\begin{tabular}{|c|c|c|c|c|c|c|c|c|c|c|}
\hline Characteristics & $Z G-1$ & $Z G-2$ & $\begin{array}{l}D W- \\
1\end{array}$ & $\begin{array}{l}D W- \\
2\end{array}$ & $\begin{array}{l}K L- \\
1\end{array}$ & $\begin{array}{l}D T- \\
116\end{array}$ & $\begin{array}{l}\text { LS- } \\
912\end{array}$ & $\begin{array}{l}\text { SJ- } \\
1\end{array}$ & $\begin{array}{l}\text { SJ- } \\
2\end{array}$ & $C A V-134^{a}$ \\
\hline Gram reaction & - & - & - & - & - & - & - & - & - & - \\
\hline Motility & + & + & - & + & - & + & + & / & / & + \\
\hline Oxidase & + & + & + & + & + & + & + & + & + & - \\
\hline O-F test & + & + & + & + & + & + & + & / & / & / \\
\hline Indole & / & / & / & / & / & / & - & / & / & + \\
\hline Urea & - & - & - & + & / & - & - & + & - & + \\
\hline ONPG & + & + & / & / & - & + & - & / & / & + \\
\hline $\mathrm{H} 2 \mathrm{~S}$ production & + & - & - & - & - & - & - & + & + & - \\
\hline Glucose(gas) & - & - & + & + & + & + & - & / & / & + \\
\hline Malonate & - & - & / & / & / & - & - & / & / & - \\
\hline $\mathrm{KCN}$ & + & + & / & / & / & - & - & / & / & + \\
\hline Nitrate reductase & + & + & / & + & + & + & + & - & - & + \\
\hline Lysine decarboxylase & + & - & - & + & + & - & + & / & / & + \\
\hline Ornithine decarboxylase & - & - & + & - & - & - & - & - & - & - \\
\hline Phenylalanine deaminase & - & - & - & + & + & - & - & / & / & - \\
\hline Dnase & + & + & - & I & / & + & + & + & + & + \\
\hline Mucate & - & - & / & / & / & - & - & / & / & / \\
\hline Esculin & + & + & / & I & I & + & + & + & + & - \\
\hline Salicin & + & + & I & / & / & - & - & - & - & - \\
\hline Amygdalin & - & - & / & / & / & - & - & / & / & - \\
\hline Gluconate & - & - & / & + & - & - & - & - & - & + \\
\hline Lactose & - & - & / & / & I & - & - & / & / & - \\
\hline Trehalose & + & + & I & / & / & + & + & / & / & / \\
\hline Xylose & - & - & - & - & - & - & - & / & / & - \\
\hline Arabinose & - & - & / & / & / & - & - & / & / & - \\
\hline Rhamnose & - & + & / & / & / & - & - & / & / & - \\
\hline Maltose & + & + & / & / & / & + & + & / & / & / \\
\hline Raffinose & - & + & + & - & - & - & - & - & - & - \\
\hline Melibiose & - & + & / & / & / & - & - & / & / & / \\
\hline Mannose & + & + & I & / & / & + & + & + & + & / \\
\hline Cellobiose & + & + & I & / & I & - & + & / & / & / \\
\hline Xylitol & - & - & - & / & / & - & - & / & / & - \\
\hline Fructose & + & + & / & / & / & + & + & / & / & / \\
\hline Sorbose & - & + & / & / & / & - & - & - & - & / \\
\hline Melezitose & - & - & / & / & I & - & - & / & / & / \\
\hline Turanose & - & - & / & / & / & - & - & / & / & / \\
\hline Adonitol & - & - & - & - & - & - & / & - & - & I \\
\hline Dulcitol & - & - & / & / & / & - & - & / & / & / \\
\hline Erythritol & - & - & I & / & / & - & - & / & / & / \\
\hline Inositol & - & - & / & / & I & - & - & - & - & - \\
\hline Mannitol & - & - & / & / & / & + & - & + & + & + \\
\hline Sorbitol & + & + & - & - & - & - & - & - & - & - \\
\hline
\end{tabular}

Note: + means positive; - means negative

aData of strain CAV-134 was reported by our group (Lü et al. 2016)

16S rRNA sequence analysis 
The $16 \mathrm{~S}$ rRNA gene sequences of the nine isolates, namely ZG-1, ZG-2, DW-1, DW-2, KL1, DT-116, LS-912, SJ-1 and SJ-2 were respectively 1402 bp, 1400 bp, 1386 bp, 1426 bp, $1507 \mathrm{bp}, 1389 \mathrm{bp}, 1426 \mathrm{bp}, 1410 \mathrm{bp}$ and $1391 \mathrm{bp}$ in length. These were submitted to the GenBank with the accession numbers of MG063196 to MG063204, respectively. Agarose gel electrophoresis of PCR products of the 16S rRNA genes from the four isolates are shown in Figure 2. The 16S rRNA sequences of the isolates were analyzed by BLAST analysis, and the $16 \mathrm{~S}$ rRNA genes of ZG-1, ZG-2, DW-1, DW-2, KL-1, DT-116, LS-912, SJ-1 and SJ-2 showed high similarities $(98.43-100 \%)$ to those of both type strain $A$. veronii ATCC $35624^{\top}(X 74684)$ and $\operatorname{ATCC} 9071^{\top}(\mathrm{AF} 410949)$. A phylogenetic tree constructed on the basis

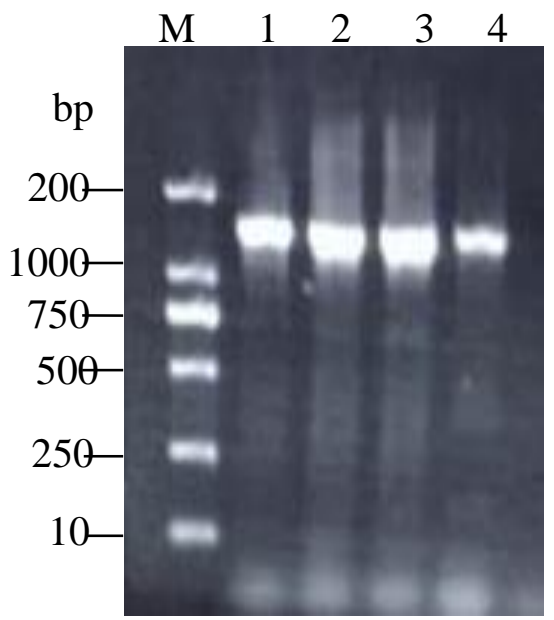

Figure 2. The electrophoresis result of PCR amplification of $16 S$ rRNA gene from the strain ZG$1, \mathrm{ZG}-2, \mathrm{DW}-1$ and $\mathrm{DW}-2$ (lines $1,2,3$ and 4 ). $M$ is DL2000 DNA Marker

of $16 \mathrm{~S}$ rRNA sequences strongly indicated that the nine isolates were most closely related to the species $A$. veronii, and were grouped into the cluster II (Figure 3). All nine isolates were identified as $A$. veronii by using morphologic, physiological, and biochemical characteristics and $16 \mathrm{~S}$ rRNA sequences analysis.

Table 2. Antimicrobial susceptibility patterns of the isolates

\begin{tabular}{|c|c|c|c|c|c|c|c|c|c|c|}
\hline Antibiotics & $Z G-1$ & $Z G-2$ & $D W-1$ & $D W-2$ & $K L-1$ & $D T-116$ & LS-912 & $S J-1$ & $S J-2$ & $C A V-134^{a}$ \\
\hline Amoxicillin & $0 / R$ & $0 / R$ & $8 / R$ & $8 / R$ & $3 / R$ & $0 / R$ & $10 / R$ & $15 / I$ & $5 / R$ & $0 / R$ \\
\hline Ampicillin & $0 / R$ & $0 / R$ & $9 / R$ & $7 / R$ & $3 / R$ & $0 / R$ & $0 / R$ & $0 / R$ & $25 / S$ & $0 / R$ \\
\hline Cefixime & / & / & $27 / S$ & $28 / S$ & $21 / S$ & $35 / S$ & / & $22 / S$ & $30 / R$ & $37 / S$ \\
\hline Cefoperazone & $34 / S$ & $32 / S$ & $21 / S$ & $30 / S$ & $26 / S$ & $24 / S$ & $31 / S$ & $30 / \mathrm{S}$ & $23 / S$ & $22 / S$ \\
\hline Cefotaxime & $47 / S$ & $35 / S$ & $38 / S$ & $39 / 5$ & $25 / S$ & $20 / S$ & $38 / S$ & $40 / S$ & $40 / S$ & $38 / S$ \\
\hline Cephalexin & $26 / S$ & $0 / R$ & $20 / S$ & $24 / S$ & $37 / S$ & $19 / S$ & $19 / S$ & $15 / I$ & $17 / I$ & $21 / S$ \\
\hline Meropenem & $22 / S$ & $15 / I$ & $12 / R$ & $18 / \mathrm{S}$ & $20 / S$ & $15 / I$ & $10 / R$ & $30 / \mathrm{S}$ & $14 / I$ & $15 / S$ \\
\hline Vancomycin & $11 / \mathrm{R}$ & $0 / R$ & $12 / R$ & $15 / \mathrm{I}$ & $10 / I$ & $0 / R$ & $0 / R$ & / & / & $0 / R$ \\
\hline Amikacin & $20 / S$ & $22 / S$ & $18 / \mathrm{S}$ & $25 / S$ & $12 / \mathrm{R}$ & $15 / I$ & $16 / I$ & $13 / \mathrm{R}$ & $16 / I$ & $21 / S$ \\
\hline Gentamycin & $0 / R$ & $0 / R$ & $19 / S$ & $18 / S$ & $21 / \mathrm{S}$ & $14 / I$ & $16 / S$ & $15 / I$ & $17 / R$ & $20 / S$ \\
\hline Kanamycin & $21 / S$ & $14 / I$ & $21 / S$ & $24 / S$ & $19 / \mathrm{S}$ & $13 / R$ & $20 / S$ & $14 / I$ & $14 / I$ & $18 / \mathrm{S}$ \\
\hline Streptomycin & $25 / S$ & $0 / R$ & $21 / S$ & $27 / S$ & $14 / I$ & $10 / R$ & $17 / \mathrm{S}$ & $12 / I$ & $18 / \mathrm{S}$ & $16 / S$ \\
\hline Neomycin & $25 / S$ & $24 / S$ & $22 / S$ & $20 / S$ & $26 / S$ & $18 / \mathrm{S}$ & $23 / S$ & / & / & $18 / \mathrm{S}$ \\
\hline Levofloxacin & $24 / S$ & $21 / \mathrm{S}$ & $22 / S$ & $29 / S$ & $34 / S$ & $23 / S$ & $18 / R$ & $25 / S$ & $22 / S$ & / \\
\hline Nalidixic Acid & $11 / \mathrm{I}$ & $12 / I$ & $12 / \mathrm{R}$ & $29 / S$ & $14 / I$ & $22 / S$ & $0 / R$ & $0 / R$ & $11 / \mathrm{I}$ & $21 / S$ \\
\hline Norfloxacin & / & / & $18 / \mathrm{S}$ & $29 / S$ & $31 / \mathrm{S}$ & $18 / \mathrm{S}$ & $13 / I$ & $20 / S$ & $15 / S$ & $21 / S$ \\
\hline Enrofloxacin & $21 / I$ & $18 / \mathrm{I}$ & $24 / S$ & $22 / S$ & $33 / S$ & $18 / \mathrm{I}$ & $28 / S$ & $22 / S$ & $22 / S$ & $22 / S$ \\
\hline Chloramphenicol & $36 / S$ & $25 / S$ & $29 / S$ & $34 / S$ & $34 / S$ & $32 / S$ & $30 / \mathrm{S}$ & $25 / S$ & $25 / S$ & $33 / S$ \\
\hline Macrodantin & 1 & 1 & $21 / \mathrm{S}$ & $21 / \mathrm{S}$ & $20 / S$ & $16 / I$ & 1 & 1 & 1 & 1 \\
\hline Rifampicin & $13 / R$ & $19 / I$ & $16 / I$ & $15 / I$ & / & $21 / S$ & $15 / R$ & / & / & $18 / \mathrm{S}$ \\
\hline Sulfisoxazole & $19 / \mathrm{S}$ & $21 / \mathrm{S}$ & $23 / S$ & $29 / S$ & / & $21 / \mathrm{S}$ & $0 / R$ & $0 / R$ & $0 / R$ & / \\
\hline sulfamethoxazole & $23 / 5$ & $0 / R$ & $12 / I$ & $32 / S$ & $\log ^{2}$ & $23 / S$ & $0 / R$ & $0 / R$ & $0 / R$ & $26 / S$ \\
\hline Florfenicol & $34 / 5$ & $39 / S$ & $28 / S$ & $33 / S$ & $37 / S$ & $36 / S$ & $25 / S$ & $25 / S$ & $30 / \mathrm{S}$ & $21 / S$ \\
\hline Trimethoprim & $23 / S$ & $0 / R$ & $18 / \mathrm{S}$ & $29 / S$ & / & $12 / \mathrm{R}$ & $0 / R$ & / & / & / \\
\hline
\end{tabular}

Note: S: susceptible; I: intermediate susceptible; R: resistant

aData of strain CAV-134 was reported by our group (Lü et al. 2016) 


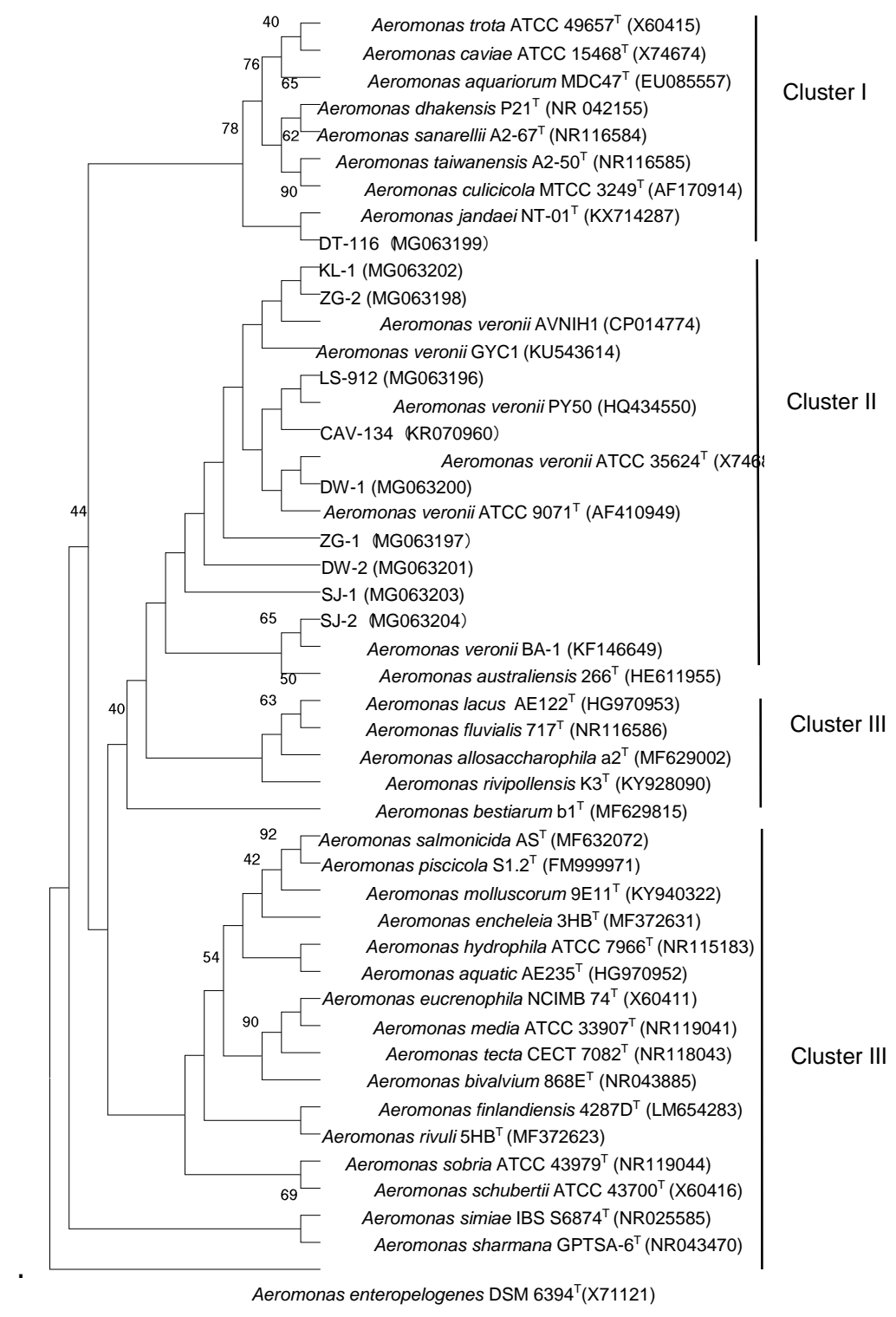

Figure 3. Phylogenetic tree analysis of Aeromonas species based on 16S rRNA nucleotide sequences. The sequences of 16S rRNA strain AVNIH1, GYC1, PY50 and BA-1 were from the references by Hughes et al. (2016), Sun et al. (2016), Cai et al. (2010) and Chi et al. (2014), respectively. The strain CAV-134 was reported by our group (Lü et al., 2016).

Antimicrobial susceptibility patterns. Antibiotics susceptibility test showed that the strains ZG-1, ZG-2, DW-1, DW-2, KL-1, DT-116, LS-912, SJ-1 and SJ-2 were all susceptible to cephalosporins (ie. cefixime, cefoperazone, cefotaxime, and cephalexin), quinolones (except for nlidixic cid), and chloramphenicol (ie. chloramphenicol, florfenicol); but all (except for SJ1 and SJ2) were resistant to penicillins (ie. amoxicillin, ampicillin), as shown in Table2.

Infection experiments. The zebrafish were infected with the isolates ZG-1, ZG-2, DW-1, DW-2, KL-1 and DT-116 after which identical symptoms were observed (see Figure 4). There were no clinical symptoms or mortalities in the control group. Bacteria with the same characteristics as $A$. veronii were re-isolated from all infected fish. The $L_{50}$ values for ZG-1, ZG-2, DW-1, DW-2, KL-1, and DT-116 were $1.15 \times 10^{6} \mathrm{CFU} / \mathrm{mL}, 1.27 \times 10^{6}$ $\mathrm{CFU} / \mathrm{mL}, 1.17 \times 10^{6} \mathrm{CFU} / \mathrm{mL}, 3.94 \times 10^{8} \mathrm{CFU} / \mathrm{mL}, 1.40 \times 10^{7} \mathrm{CFU} / \mathrm{mL}$ and $1.18 \times 10^{6} \mathrm{CFU} / \mathrm{mL}$, respectively. 


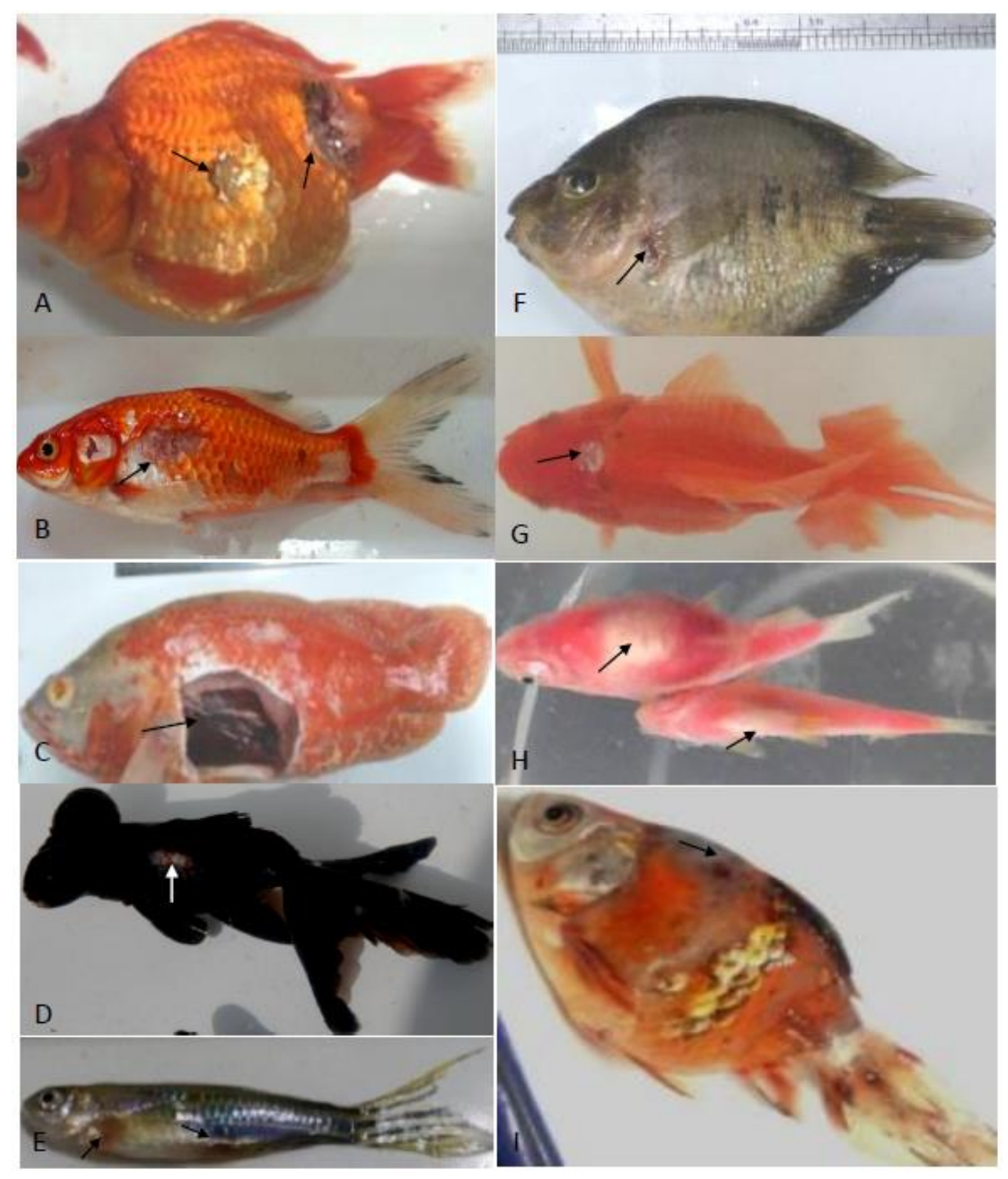

Figure 4. Clinic signs of ornamental fish infected with Aeromonas veronii $(A, D, G, I$ : goldfish Carassius auratus; B: crucian carp Cyprinus carpio koi; C: oscar Astronotus ocellatus; E, H: zebrafish Danio rerio; F: parrotfish Amphilophus A, B, D, G and I: arrows indicate typical skin ulceration; C: arrow indicate bleeding of internal organs; $E, H$ : arrows indicate abdominal distension. and bleeding; $\mathrm{F}$ : hemorrhage near its pectoral fin.

Histological manifestation. Histopathology of zebrafish infected with $A$. veronii revealed gill lamellae damage, mucus cell proliferation, and leukocyte infiltration of gill filaments, separation of superficial and deep layer in skin, congestion of central veins and necrosis of the hepatic cell, glomerulus hemorrhage, and glomerular capsule filled with blood cells in the kidney. The histopathology of control and infected zebrafish are shown in Figure 5. 

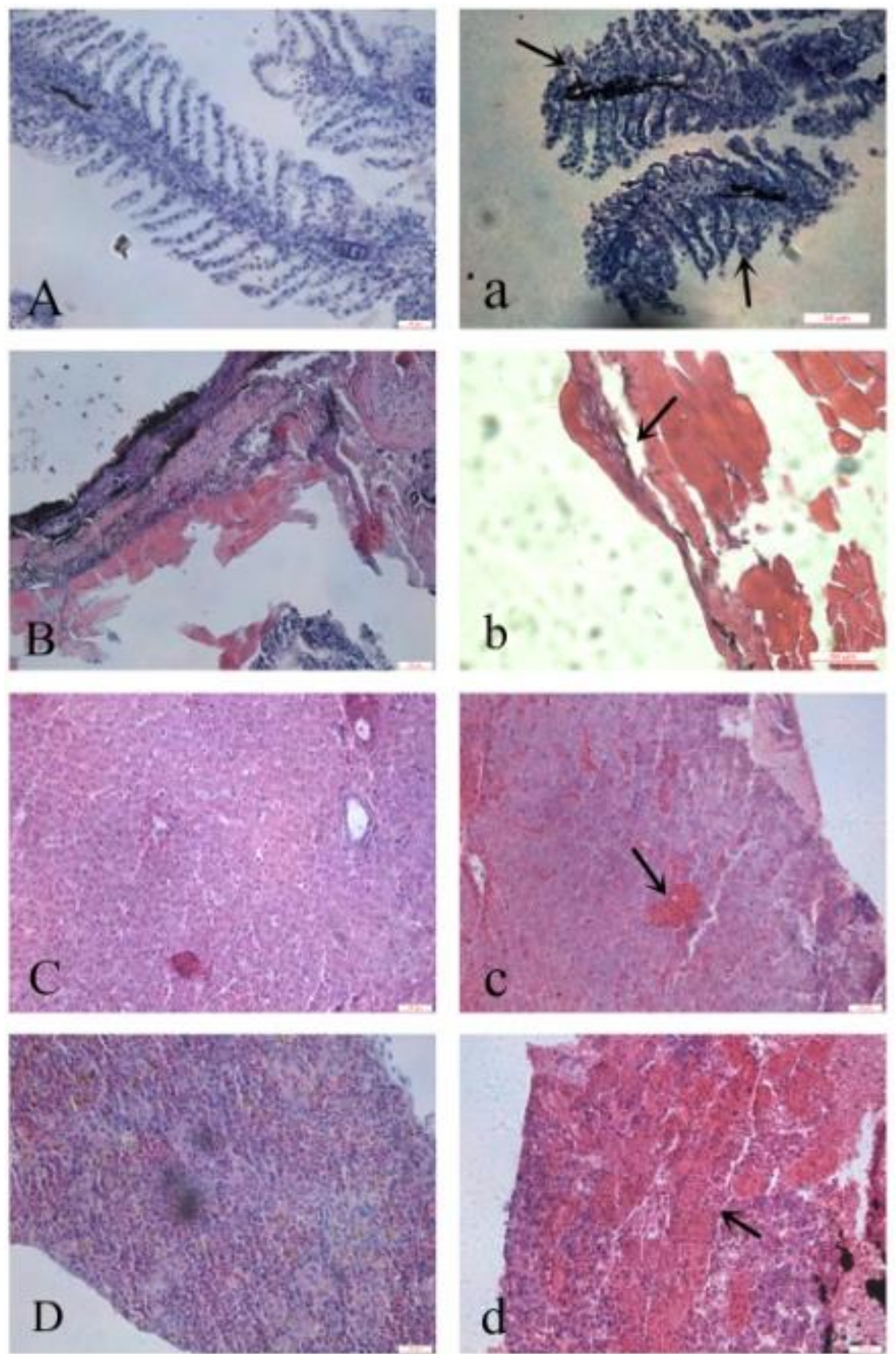

Figure 5. Histological changes of the zebrafish infected with Aeromonas veronii. (A), (B), (C), (D) were gill, skin, liver, and kidney of control fish; (a) gill showing leukocyte infiltration of gill filaments (arrows); (b) skin showing separation of boundary layer in skin (arrow); (c) liver showing congestion of central veins (arrow); (d) kidney showing glomerulus hemorrhage (arrow).

\section{Discussion}

Aeromonas veronii is a Gram-negative, rod-shaped bacterium found in fresh water, sewage, soil, and food (Kirov et al., 2010; Igbinosa et al., 2013; Zhang et al., 2014). In humans, $A$. veronii often cause diarrhea, pneumonia, and hemolytic disease (Janda et al., 2010; Hassan et al., 2011). In recent years, it was reported that $A$. veronii were associated with skin ulcerative syndrome (SUS) in channel catfish ictalurus lunetas (Huang et al., 
2012), Ictalurus punctatus (Liu et al., 2015), goldfish Carassius auratus (Lü et al. 2016), and crucian carp Cyprinus carpio koi, and Siamese fighting fish Betta splendens (Jagoda et al., 2014), and were also considered epizootic causative agents of skin ulceration, dropsy, fin rot, hemorrhages, and septicemia. A. veronii were isolated from diseased zebrafish, caused exophthalmia, dropsy and bleeding symptoms (Kar et al. 2016). The 16S rRNA gene sequence is commonly used in analysis of the phylogenetic tree of bacterial genera (Cai et al., 2012; Lü et al., 2016). However, difficulties often arise when using 16S rRNA sequences for species identification for Aeromonas spp. due to its smaller discriminatory power (Yánez et al., 2003; Sun et al., 2016). In this study, nine $A$. veronii strains were isolated from diseased ornamental fish and a phylogenetic tree was constructed on the basis of $16 \mathrm{~S}$ rRNA sequences. These strongly indicated that the nine isolates from the diseased ornamental fish were most closely related to $A$. veronii, and were grouped into cluster II that included the strains ATCC $35624^{\top}$ and ATCC $9071^{\top}$, CAV-134 from goldfish (Lü et al., 2016), PY50 from Chinese long-snout catfish (Cai et al., 2012), and BA-1from common carp (Chi et al., 2014), and AVNIH1 from the patients (Hughes et al., 2016), suggesting that the $A$. veronii strains may be a potential zoonotic pathogen. Additionally, $A$. veronii are divided into biovars of $A$. veronii bv. veronii and $A$. veronii bv. sobria based on different biochemical for ornithine decarboxylase, esculinand and salicin (Bowman, 2005; Lorén et al., 2010; Zhu et al., 2016), but were very similar based on the phylogenetic analysis of 16S rRNA sequences (Küpfer et al., 2006; Sun et al., 2016). However, nine isolates were characterized for further future determination of biotype.

In this study, our results with histopathology of zebrafish infected by $A$. veronii is an important beginning for demonstrating the pathogenic mechanism in ornamental fish. Previous reports demonstrated that $A$. veronii was the common pathogen in fish (Han et al., 2008; Cai et al., 2012; Abolghait et al., 2013). In this study, isolated $A$. veronii were strongly virulent to ornamental fish which displayed skin ulcerative syndrome, leukocyte infiltration of gill filaments, necrosis of the hepatic cell, and glomerulus hemorrhage. Similar alterations have also been reported in fish infected by Aeromonas spp (Chen et al., 2012; Eathel Poline et al., 2014; Dong et al., 2017). However, limited literature is available about the histological observation of fish infected by $A$. veronii. (Dong et al., 2017).

The antibiotic susceptibility will provide information for clinical treatment and infection prevention caused by $A$. veronii in fish (Janda et al., 1985; Cai et al., 2012; sun et al., 2016; Lü et al., 2016). Our data revealed that the nine isolates were all susceptible to cephalosporins, which is in accordance with the results of $A$. veronii isolated from ornamental fish (Joseph et al., 1991; Yu et al., 2010; Sreedharan et al., 2011; Cai et al., 2012). However, they were different for $A$. veronii isolated grass carp Ctenopharyngodon idellus susceptible to kanamycin, sulfamethoxazole, and chloromycetin, which may be associated with the bacterial origin, aquatic environment, and clinical medication (Martínezmurcia et al., 2008; Wei et al., 2013).

In this study, we confirmed that representative strains of $A$. veronii are highly pathogenic to zebrafish, and that $A$. veronii is the pathogen that caused the outbreaks of ulcerative syndrome in the tested ornamental fish. These data can provide a scientific reference for characterization of $A$. veronii and future prevention of this disease in ornamental fish.

\section{Acknowledgements}

This study was supported by the National Natural Science Foundation of China (No. 31272692), Key Scientific Research Project Universities and Colleges in Henan province (No. 17A240001), Team of Provincial Science and Technology Innovation of Henan High Education (No. 15IRTSTHN018), Natural Science Foundation of Tianjin city (No. 16JCZDJC33500, 15JCZDJC34000) and Innovation Team of Tianjin Fisheries Research System (No. ITTFRS2017009).

\section{References}

Abolghait, S. K., Mohamed, M. F., Aly, S. M., Garbaj, A. M., \& Moawad, A. A, 2013, Attenuated virulence of pigment-producing mutant of Aeromonas veronii, bv. sobria, in hela cells and nile tilapia ( oreochromis niloticus ). Int J Vet Sci Med., 1(1): 43-47. 
Aijun, L., Hu, X., Lu, Z., Zhu, A., Cao, C., \& Jiang, J, 2011, Isolation and characterization of citrobacter spp. from the intestine of grass carp ctenopharyngodon idellus. Aquaculture, 313(1): 156-160.

Bowman JP., 2005, Genus I. Aeromonas. In: Bergey's Manual of Systematic Bacteriology (eds. by D.J. Brenner, N.R. Krieg \& J.T. Staley), vol. 2, Part B, pp. 557-577.

Cai, S. H., Wu, Z. H., Jian, J. C., Lu, Y. S., \& Tang, J. F, 2012, Characterization of pathogenic Aeromonas veronii bv. veronii associated with ulcerative syndrome from chinese longsnout catfish (leiocassis longirostris günther). Brazilian J Microbiol: publication of the Brazilian Society for Microbiology., 43(1): 382-388.

Chen, Y. F., Liang, R. S., Zhuo, X. L., Wu, X. T., \& Zou, J. X, 2012, Isolation and characterization of Aeromonas schubertii from diseased snakehead, channa maculata (lacepède). J Fish Dis, 35(6): 421-430.

Chi, C., Jiang, B., Yu, X. B., Liu, T. Q., Xia, L., \& Wang, G. X, 2014, Effects of three strains of intestinal autochthonous bacteria and their extracellular products on the immune response and disease resistance of common carp (cyprinus carpio). Fish Shellfish Immunol, 36(1): 9-18.

Dong, H. T., Techatanakitarnan, C., Jindakittikul, P., Thaiprayoon, A., Taengphu, S., \& Charoensapsri, W., et al, 2017, Aeromonas jandaei and Aeromonas veronii caused disease and mortality in nile tilapia, oreochromis niloticus (I.). J Fish Dis. 1-9.

Han, H. J. J., Taki, T. T., Kondo, H. K., Hirono, I. H., \& Aoki, T. A, 2008, Pathogenic potential of a collagenase gene from Aeromonas veronii. Canadian J Microbiol, 54(1): 110.

Han, Z., Lv, A., Shi, H., Sun, J., Xing, K., \& Hu, X., et al, 2017, Isolation, identification and characterization of shewanella algae from reared tongue sole, cynoglossus semilaevis Günther. Aquaculture, 468: 356-362.

Hassan, A., Usman, J., Kaleem, F., Omair, M., Khalid, A., \& Iqbal, M, 2011, Aeromonas veronii biovar sobria gastoenteritis: a case report. Archives of Clinical Microbiol 2(5:3):1-3.

Huang, X. L., Wang, K. Y., Du, Z. J., Yi, G., \& Deng, Y. Q, 2012, Identification, isolation and in vitro antimicrobial susceptibility testing of Aeromonas veronii associated with an acute death of channel catfish (ictalurus lunetas) in china. African J Biotechnol, 9(14): 2161-2164.

Hughes, H. Y., Conlan, S. P., Lau, A. F., Dekker, J. P., Michelin, A. V., \& Youn, J. H., et al, 2016, Detection and whole-genome sequencing of carbapenemase-producing Aeromonas hydrophila isolates from routine perirectal surveillance culture. J Clin Microbiol, 54(4): 1167-1170.

Igbinosa, I. H., Chigor, V. N., Igbinosa, E. O., Obi, L. C., \& Okoh, A. I, 2013, Antibiogram, adhesive characteristics, and incidence of class 1 integron in Aeromonas species isolated from two south african rivers. Biomed Res Int., 2013(132) : 127570.

Igbinosa, I. H., \& Okoh, A. I, 2013, Detection and distribution of putative virulence associated genes in aeromonas species from freshwater and wastewater treatment plant. J Basic Microbiol, 53(11): 895-901.

Jagoda, S. S., Wijewardana, T. G., Arulkanthan, A., Igarashi, Y., Tan, E., \& Kinoshita, S, 2014, Characterization and antimicrobial susceptibility of motile aeromonads isolated from freshwater ornamental fish showing signs of septicaemia. Dis Aquatic Org, 109(2): 127-137.

Janda, J. M., \& Abbott, S. L, 2010, The genus Aeromonas: taxonomy, pathogenicity, and infection. Clin Microbiol Rev, 23(1): 35-73.

Janda, J. M., \& Motyl, M. R, 1985, Cephalothin susceptibility as a potential marker for the Aeromonas sobria group. J Clin Microbiol, 22(5): 854-855.

Joseph, S. W., Carnahan, A. M., Brayton, P. R., Fanning, G. R., Almazan, R., \& Drabick, C., et al, 1991, Aeromonas jandaei and Aeromonas veronii dual infection of a human wound following aquatic exposure. J Clin Microbiol, 29(3): 565-569.

Kar, D, 2016, Epizootic Ulcerative Fish Disease Syndrome.

Kirov S M, Fiona B, 2010, Exotoxin production by Aeromonas spp. in foods. Letters in Applied Microbiology, 17(5): 208-211.

Küpfer, M., Kuhnert, P., Korczak, B. M., Peduzzi, R., \& Demarta, A, 2006, Genetic relationships of Aeromonas strains inferred from 16s rRNA, gyrb and rpob gene sequences. Int J Syst Evolut Microbiol, 56(12): 2743-2751.

Liu D., Geng Y., Wang K., Defang Chen D., Huang Xiao L., Ou Y., He C.L., Zhong Z.J., Lai W., 2015. Aeromonas veronii infection in cultured channel catfish, Ictalurus punctatus, in southeast China, 8 pages. Isr J Aquacult.- Bamidgeh, [IJA_68.2016.1225]. 
Liu, H., Gao, L., Shi, X., Gu, T., Jiang, Y., \& Chen, H, 2004, Isolation of spring viraemia of carp virus (svcv) from cultured koi (cyprinus carpio koi) and common carp (c. carpio carpio) in p.r. china. Bulletin- European Association of Fish Pathologists, 24(4): 194-202.

Lorén, J. G., Farfán, M., Miñanagalbis, D., \& Fusté, M. C, 2010, Prediction of wholegenome DNA G+C content within the genus Aeromonas based on housekeeping gene sequences. Syst Appl Microbiol, 33(5): 237-242.

Lü, A.J., Song, Y.J., Hu, X.C., Sun, J.F., Li, L., Pei, C., Zhang, C., \& Nie G.X., 2016, Aeromonas veronii, associated with skin ulcerative syndrome, isolated from the goldfish (Carassius auratus) in China. Isr J Aquacult. - Bamidgeh, 1321(68): 1-10.

M. Eathel Poline et al, 2014, Histological changes brought by Aeromonas hydrophila on some cells of spotted murrel, Channa punctatus (Bloch). Int J Life Sci Educational Res, 3(1): pp. 1-6.

Martínez-Murcia, A J., Saavedra MJ, Mota VR, Maier T, Stackebrandt E, and S Cousin, 2008, Aeromonas aquariorum sp. nov., isolated from the aquaria of ornamental fish. Int J Syst Evol Microb., 58(5): 1169-1175.

Queipo-Ortuño, M. I., De, D. C. J., Macias, M., Bravo, M. J., \& Morata, P, 2008, Preparation of bacterial DNA template by boiling and effect of immunoglobulin $g$ as an inhibitor in real-time pcr for serum samples from patients with brucellosis. Clinical \& Vaccine Immunol Cvi, 15(2): 293-296.

Sreedharan, K., Philip, R., \& Singh, I. S, 2011, Isolation and characterization of virulent Aeromonas veronii from ascitic fluid of oscar astronotus ocellatus showing signs of infectious dropsy. Dis Aquatic Org, 94(1): 29-39.

Sreedharan, K., Philip, R., \& Singh, I. S, 2012, Virulence potential and antibiotic susceptibility pattern of motile aeromonads associated with freshwater ornamental fish culture systems: a possible threat to public health. Brazilian J Microbiol, 43(2): 754-765.

Suely, E. B. N., Andrew, M., \& Prazeres, R. D. D, 2010, Characterization of Aeromonas species isolated from an estuarine environment. Brazilian J Microbiol, 41(2): 452-460.

Sun, J., Zhang, X., Gao, X., Jiang, Q., Wen, Y., \& Lin, L, 2016, Characterization of virulence properties of Aeromonas veronii isolated from diseased gibel carp (carassius gibelio). Int J Molec Sci, 17(4): 1061-1068.

Teng, Y., Liu, H., Lv, J. Q., Fan, W. H., Zhang, Q. Y., \& Qin, Q. W, 2007, Characterization of complete genome sequence of the spring viremia of carp virus isolated from common carp (cyprinus carpio) in china. Archives of Virology, 152(8): 1457-1465.

Wang HJ., Wang L., Gou XL., Long ZM., and J Zhao, 2013b, Study on drug resistance in Aeromonas veronii isolated from different fish. China Animal Husbandry \& Veterinary Medicine, 159-164.

Wei, L. L., Wang, Z. R., \& Yang, Z. Q, 2013, Isolation and identification of two Aeromonas strains from grass carp ctenopharyngodon idellus. Fish Sci, 32(6):348-352.

Yang XQ, 2013, Isolation identification and susceptibility test of the pathogenic Aeromonas veronii from goldfish (Carassius auratus). Modern Agricultural Sciences, 6-161. Yu, J. H., Han, J. J., Kim, H. J., Kang, S. G., \& Park, S. W, 2010, First report of Aeromonas veronii infection in farmed israeli carp cyprinus carpio in korea. J Fish Pathol, 23(2): 165-176.

Zhang, Y., Zhou, Z., Liu, Y., Cao, Y., He, S., \& Huo, F., et al, 2014, High-yield production of a chitinase from Aeromonas veronii b565 as a potential feed supplement for warm-water aquaculture. Appl Microbiol Biotechnol, 98(4): 1651-1662.

Zhou G., Xie J, Zhou QL, Xi BW, and P Xu. 2012, Pathogenicity and antibiotic resistance of Aeromonas from bream Megalobrama amblycephala ponds and the differences between different niche. Jiangsu Agricult Sci, 192-196.

Zhu, M., Wang, X. R., Li, J., Li, G. Y., Liu, Z. P., \& Mo, Z. L, 2016, Identification and virulence properties of Aeromonas veronii bv. sobria isolates causing an ulcerative syndrome of loach misgurnus anguillicaudatus. J Fish Dis, 39(6): 777-781. 